\title{
Educação ambiental e enfermagem: uma integração necessária
}

\author{
Environmental education and nursing: a necessary integration
}

Educación ambiental y enfermería: una integración necesaria

\section{Eveline Pinheiro Beserra', Maria Dalva Santos Alves, Patrícia Neyva da Costa Pinheiro, Neiva Francenely Cunha Vieira' \\ 'Universidade Federal do Ceará. Departamento de Enfermagem. Fortaleza, CE}

Submissão: 24/07/2009

Aprovação: 13/07/2010

\section{RESUMO}

A Questão ambiental deve fazer parte das discussões nas ações educativas, pois este debate favorece para Que as pessoas reflitam o Que seja ecologicamente saudável. Objetivou-se refletir sobre Promoção da saúde, educação ambiental e Enfermagem. Trata-se de um estudo reflexivo sobre saúde ambiental em três focos: Promoção da saúde ambiental e humana; Ações educativas em saúde Ambiental e Enfermagem e Educação em saúde. Observou-se que a educação ambiental é um tema Que engloba o bem-estar humano, sendo necessárias ações de promoção da saúde Que capacitem o indivíduo e a comunidade a exercerem seu empoderamento e autonomia. Descritores: Educação em saúde; Educação ambiental; Enfermagem.

\section{ABSTRACT}

Environmental issue should be discussed in educational actions, because this debate leads people to reflect on what is ecologically healthy. It was aimed to reflect on Health promotion, Environmental education and Nursing. This is a reflexive study on environmental health in three groups: Promotion of environmental and human health; Educational actions in Environmental health; and Nursing and Health education. It was verified that environmental education is a theme that includes human well-being, being necessary actions of health promotion that Qualify individual and community to practice their empowerment and autonomy.

Key words: Health education; Environmental education; Nursing.

\section{RESUMEN}

La cuestión ambiental debe formar parte de los debates sobre la educación, porque este debate favorece para Que las personas reflexionen sobre lo que es ecológicamente sano. Se pretendió reflexionar sobre Promoción de la salud, educación ambiental y Enfermería. Se trata de un estudio reflexivo sobre la salud ambiental en três focos: Promoción de la salud ambiental y humana, Acciones educativas para la salud Ambiental y Enfermería y Educación en salud. Se señaló que la educación ambiental es un tema Que abarca el bienestar humano, siendo necesarias acciones de promoción de la salud Que permitan al individuo y a la comunidad a ejerceren su empoderamiento y autonomía.

Descriptores: Educación en salud; Educación ambiental; Enfermería. 


\section{INTRODUÇÃO}

As Questões ambientais são, atualmente, um problema de saúde, uma vez Que a sociedade busca se desenvolver economicamente, muitas vezes sem a devida preocupação com o meio ambiente. Os seres humanos são responsáveis pelos danos causados à natureza, por isso torna-se necessária a reflexão acerca do bem-estar ecológico e humano.

Neste aspecto, a educação ambiental não é neutra e, tampouco, aceitará a conformidade, almejando sempre a transformação de tudo Que causa ou poderá causar problemas ao bem-estar do planeta $^{(1)}$.

Diferentes campos de atuação interdisciplinar unem-se para alcançar medidas de conscientização sobre os problemas ambientais, pois os prejuízos à natureza são de responsabilidade de cada indivíduo. Neste contexto, a educação pode ser vista como um meio Que, efetivamente, contribuirá para um futuro sustentável, a partir de intervenções coerentes com a contemporaneidade, como também conduzindo os seres humanos a perceberem a importância da auto-determinação para executar ações saudáveis em seu ambiente $^{(2)}$.

Inserem-se nessa discussão as atividades educativas Que se propõem a capacitar as pessoas para o compromisso com o meio ambiente, pois, Quando estas atividades são elaboradas de maneira eficaz, são capazes de levar as pessoas a refletirem sobre a produção excessiva de lixo e a tornarem-se agentes ativos para favorecer um ambiente saudável e sem prejuízo ambiental.

Ampliamos a visão sobre educação partindo da afirmativa Que a educação em saúde é uma forma de garantir a dignidade da pessoa humana a partir de elementos teóricos direcionadores ${ }^{(3)}$.

Nesse contexto, a educação ambiental precisa substancialmente conceber a interdisciplinaridade, Quando diferentes áreas de conhecimento se agregam para tornar mais fácil a compreensão sobre a complexidade Que envolve o ambiente.

A saúde ambiental, nas últimas décadas, está sendo vista como o conjunto de condutas voltadas para a preservação do meio ambiente, sendo item norteador de ética nas relações sociais, como também para a compreensão da realidade dos problemas que afetam diretamente o ecossistema ${ }^{(4)}$.

Para elaborar estratégias educativas sobre saúde ambiental, é necessário, inicialmente, discutir sobre todo o processo de desequilíbrio ambiental, buscando conhecer a realidade para interferir de forma eficaz, reavaliando práticas sanitárias, para Que, posteriormente, sejam executadas estratégias concretas de educação em saúde, Que permitam a proteção e a promoção da saúde de forma integral às comunidades, como também capacitar o indivíduo e a sociedade a realizarem ações saudáveis para o meio ambiente, levando-os a uma consciência ecológica.

É responsabilidade de todos proteger o ambiente contra a degradação a fim de Que as gerações futuras não sofram com a inconseqüência deste agravo. Há, portanto, a necessidade de que sejam formuladas políticas de proteção e de promoção do ambiente saudável, e, além disso, é preciso Que processos participativos dos cidadãos sejam incentivados nos trabalhos de sensibilização para as Questões ambientais ${ }^{(5)}$.

A sociedade deve tomar consciência dos diferentes aspectos ambientais Que colocam em perigo nosso planeta e as pessoas, pois o ser humano é diretamente ligado à natureza e sem ela a vida seria inviável.

A enfermagem está diretamente relacionada ao cuidado humano e à Qualidade de vida por meio de ações de promoção da saúde, pois, assim como outras áreas, objetiva manter o ambiente saudável. Nessa perspectiva, esse artigo se propõe a refletir sobre promoção da saúde, educação ambiental e enfermagem.

Este artigo tem a intenção de refletir sobre Promoção da saúde ambiental e humana; Ações educativas em saúde Ambiental e Enfermagem; e Educação em Saúde, caracterizando-se como um artigo reflexivo.

\section{PROMOÇÃO DA SAÚDE AMBIENTAL E HUMANA}

A Promoção da Saúde identifica-se com um estilo de vida mais saudável, por meio de ações Que contemplem alimentação de Qualidade, moradia e educação, bem como a interação do homem com o meio em Que ele vive, sendo o ambiente saudável um dos fatores Que colaboram com o seu desenvolvimento com vistas à saúde ${ }^{(6)}$, como também se configura como uma medida norteadora, em diferentes âmbitos, como político, assistencial e educacional, para contribuir com as transformações das ações de saúde ${ }^{(7)}$.

A Carta de Otawa, documento Que direcionou as bases operacionais de promoção da saúde, afirma Que as condições e reQuisitos para a saúde são: paz, educação, habitação, justiça social, como também, um ecossistema estável e recursos sustentáveis ${ }^{(8)}$. Completando esses requisitos, existe a necessidade de conceber a promoção da saúde de forma ampla, relacionando-a a políticas públicas e à intersetorialidade, para implementar estratégias visando a melhorar os níveis de saúde ${ }^{(9)}$.

Os eixos da promoção da saúde, também descritos na Carta de Otawa (a saber: Elaboração e implementação de Políticas Públicas saudáveis, Criação de ambientes favoráveis à saúde, Reforço da ação comunitária, Desenvolvimento de habilidades pessoais e Reorientação do sistema de saúde), têm íntima relação com a saúde ambiental, caracterizando-se por favorecer o desenvolvimento de habilidades pessoais para impulsionar as pessoas para lutarem por melhores condições, servindo de pilar para o reforço da ação comunitária. Outro eixo capacita as comunidades a serem atuantes nos problemas específicos Que a impedem de ser saudáveis. E mais outro eixo da promoção dá seguimento à criação de ambientes favoráveis à saúde. Esta é uma luta constante, uma vez que o prejuízo ambiental e humano pode desequilibrar o ecossistema. Esses êxitos também se articulam com a elaboração de políticas públicas saudáveis, por meio de estratégias sustentáveis no município e da reorientação do serviço de saúde, sendo estes últimos consequências de ações de indivíduos e de coletividades empoderadas de sua ação social.

Empoderamento, conceituado por o Paulo Freire, é a capacidade de um grupo ou pessoa de realizar, por si, mudanças e atitudes Que levam ao desenvolvimento próprio(10-11). Logo, tornam-se importantes medidas Que favoreçam a geração de ambientes apropriados ao bem-estar humano e ecológico, assim como propostas pedagógicas libertadoras, comprometidas com o desenvolvimento da solidariedade e da cidadania, orientadas para ações cuja essência está na melhoria da Qualidade de vida e na promoção do ser humano. 
Neste contexto, a Educação em Saúde é uma estratégia Que está inserida nesse campo de atuação, uma vez Que visa capacitar o indivíduo a uma melhor Qualidade de vida, ampliando o processo Que abrange a participação de toda a população no contexto de sua vida cotidiana, e não apenas das pessoas sob o risco de adoecer, levando-os a refletir sobre sua condição real no ambiente na Qual vivem $^{(10)}$

Para Souza e Grundy(12), a promoção da saúde tem sido conceituada como o processo Que capacita a comunidade a exercer e aumentar o controle sobre a sua saúde, favorecendo ao empoderamento.

O desenvolvimento próprio do indivíduo e da comunidade favorece sua atuação em diferentes espaços, dentre eles o meio no Qual está inserido. Na saúde ambiental, para Que se possam explorar adequadamente os diversos po-tenciais, é necessário, antes de tudo, garantir a manutenção de um ecossistema equilibrado, sen-do fundamental tanto a implementação de mecanismos de conservação ambiental, valorizando a água, o ar e a terra, Quanto compreender as relações sociais de cada contexto.

A inter-relação dos conceitos de Educação em Saúde e de Promoção da Saúde atinge um significado ampliado do processo de capacitação das pessoas, haja vista proporcionar uma abordagem sócio-educativa. Dessa forma, são assegurados os conhecimentos, as habilidades e a formação da consciência crítica do cidadão para a tomada de decisões com maior responsabilidade sócio-ambiental, incluindo políticas públicas e a luta por ambientes saudáveis. Sob esse enfoque, trabalha-se com a idéia de Que as ações de Educação em Saúde fundamentam-se numa concepção de Qualidade de vida do cotidiano dos indivíduos ${ }^{(10)}$.

Inserido no contexto das ações de educação, o pensamento de Paulo Freire conceitua a educação como princípio da ação cultural, relacionada ao processo de consciência crítica, visto como uma educação apresentadora de problemas, tendo a pedagogia crítica, como práxis cultural, contribuído para elevar a consciência das pessoas, como também uma revolução pedagógica em sua essência e significativa para todos ${ }^{(12)}$.

Portanto, a ideologia de Freire preocupa-se com a inserção do indivíduo na sociedade, levando-o a uma reflexão crítica de sua condição de vida. Nesse cenário, os educadores buscam favorecer maior Qualidade de vida para as pessoas, famílias e comunidades por meio de ações dialógicas.

Logo, a Educação é um importante instrumento para as ações de intervenção na saúde ambiental capacitarem o individuo e a comunidade a refletirem sobre os problemas ambientais existentes.

\section{AÇÕES EDUCATIVAS EM SAÚDE AMBIENTAL}

As práticas educativas devem alicerçar-se em ações multidisciplinares, havendo uma convergência na integração dos problemas socioambientais com sua prevenção e solução. Tal processo deve orientar-se por uma dinâmica Que permita um caminhar metodológico de ações Que favoreçam o trabalho em equipe e a formação de condutas conscientes, relacionadas a valores pessoais como respeito, solidariedade, prudência e cidadania em vista da sustentabilidade sócio-ambiental ${ }^{(13)}$.

Complementando os valores acima, a educação é essencial para Que haja atitude ética perante a Questão ambiental. O educador é compreendido como a pessoa capaz de desenvolver e exercer papel ativo de troca na construção de novas relações no mundo e interrelações da sociedade com o meio ambiente para a consolidação do compromisso ecológico, cabendo essa atuação educativa a todas as pessoas, grupos e comunidades, uma vez Que um ambiente saudável é inerente à vida.

$\mathrm{Na}$ ação para promoção da saúde no contexto da saúde ambiental, diversas profissões interligam-se, utilizando instrumentos próprios com um só propósito: promover saúde. Daí a importância de discutir o tema, Que engloba o bem-estar humano e ecológico, tendo como finalidade elaborar medidas consistentes cabíveis. Neste contexto, o cuidado de enfermagem integra-se por ser capaz de direcionar intervenções educativas sobre as vulnerabilidades ambientais a fim de diminuir a possibilidade de acarretar danos ecológicos e, consequentemente, humanos.

A Enfermagem preocupa-se com o bem-estar do indivíduo, de sua família e da comunidade, devendo ser executado juntamente com um sentimento de solidariedade, sem desconsiderar Que o ambiente é um fator relacionado à saúde humana.

É preciso compreender Que a tensão entre ampliação e/ou redução da esfera pública evidencia a pergunta sobre as possibilidades de crescimento, necessitando de uma política orientada pelo ideário ecológico, uma vez Que seu apelo busca legitimar-se a partir dos riscos dos desequilíbrios ambientais ${ }^{(14)}$.

A degradação ambiental coloca em risco as gerações futuras, Que sofrerão com a inconseQüência das ações, necessitando de intervenções Que minimizem os prejuízos à natureza por meio de atitudes conscientes Que concebam a saúde ambiental como alicerce para o bem-estar humano.

Além da necessidade permanente de integração entre educação em saúde e educação ambiental devido à complexidade do tema, também deve ser enfatizada a integração entre outros seguimentos da sociedade na tentativa de relacionar educação e meio ambiente ${ }^{(13)}$.

Outro aspecto tocante a essa temática é a ética, Que deve alicerçar a reflexão coletiva sobre o compromisso ambiental, favorecendo discussões acerca de saúde, cidadania e meio ambiente na busca de solucionar os desafiantes problemas sobre esses temas.

Essa reflexão deve oportunizar a compreensão da formação de novos atores sociais, articulados para a apropriação da natureza, para um processo educativo articulado e compromissados com a sustentabilidade, apoiando-se numa lógica Que privilegie o diálogo e a interdependência de diferentes áreas de saber contra a degradação permanente do meio ambiente e do seu ecossistema. Isto envolve uma necessária articulação com a produção de sentidos sobre a educação ambiental|(15).

Existe a necessidade da ação intersetorial articulada para resolver o problema voltado para o ecossistema, favorecendo os indivíduos e levando a comunidade ao empoderamento diante das Questões ambientais, fazendo com Que as pessoas percebam a problematização, dando ênfase à complexidade dos processos sócioambientais.

A saúde ambiental, com base na vida cotidiana, nas suas necessidades e nos interesses pessoais e coletivos Que envolvem a ecologia, permite a reflexão crítica sobre a importância da formação de um espaço Que propicie a problematização sobre a saúde ambiental, visando o preparo de sujeitos comprometidos com o meio ambiente. 
Nesse cenário, torna-se necessária a construção do conhecimento científico para colaborar na formação de um pensamento crítico, baseado em conceitos atualizados, Que favoreçam uma postura participativa das comunidades a fim de Que possam contribuir para a melhoria da Qualidade de vida, tendo como objetivo comum a educação em saúde e a educação ambiental $^{(16)}$.

\section{ENFERMAGEM E EDUCAÇÃO EM SAÚDE}

A Enfermagem, como profissão educadora, deve inserir-se nesse campo de atuação efetivamente por meio de ações de Promoção da Saúde que capacitem o indivíduo e a comunidade a exercerem empoderamento e autonomia, bem como reflexão crítica para uma mudança de comportamento comprometida com a saúde ambiental. Trata-se, contudo, do desafio de capacitar pessoas para realizarem condutas ecologicamente corretas, uma vez Que o desenvolvimento se encontra continuadamente estimulado, muitas vezes deixando a sustentabilidade à margem.

Os enfermeiros buscam um equilíbrio na realização de ações de promoção da saúde contextualizados na situação real, sendo valiosa a compreensão dessas ações nos cuidados de saúde primários ${ }^{(17)}$. Diante desta conduta, torna-se necessário refletir sobre como atividades educativas na saúde ambiental podem inseriro enfermeiro em seu campo.

Mediante ações de promoção da saúde, os enfermeiros têm papéis diferentes na contribuição da saúde dos indivíduos e das comunidades, sendo eles os mais adequados para efetuarem essas implementações ${ }^{(18)}$. Enfermeiros integrados à equipe da Estratégia da Saúde da Família encontram-se próximos à comunidade e convivem com suas dificuldades, sejam sociais, econômicas ou ambientais, podendo buscar alternativas Que as minimizem ou solucionem.

É preciso Que o enfermeiro busque um caminho para a estruturação de ações coletivas, identificando a realidade, bem como articulando diferentes aspectos Que englobam a integração intersetorial em prol da saúde ambiental, necessitando de uma prática comprometida com o bem-estar ecológico.

É preciso, também, realizar ações de educação em saúde Que gerem oportunidade de reflexão sobre os hábitos da população, para Que se tornem aptos a transformar a realidade ${ }^{(19)}$. A consciência ambiental é uma decisão particular Que promove mudança de comportamento.

O profissional de Enfermagem pode capacitar comunidades por meio de ações pedagógicas a partir da vida cotidiana, das necessidades e dos interesses pessoais e coletivos que envolvem a saúde ambiental, pois este fato é uma necessidade global. Deve-se refletir sobre a importância da abertura de um espaço de formação Que propicie reflexão, problematização, crítica e articulação, apontando o comprometimento com a construção de sujeitos Que incorporem posturas éticas, de solidariedade, de consciência cidadã e de compromisso social, atuando de forma responsável com o meio ambiente, tudo isso alicerçado em práticas pedagógicas efetivas para o processo de mudança ${ }^{(20)}$.

Atualmente, observa-se, com frequência, a má Qualidade de vida causada pela não conservação a natureza. Esta realidade gera a preocupação com a vitalidade e com a diversidade do planeta Terra, bem como com o cuidado de seu próprio meio-ambiente. Para isso torna-se necessário construir uma alfabetização ecológica, implicando numa ética do cuidado. Logo, o enfermeiro pode intervir nas Questões ambientais, uma vez Que o cuidado é uma ação essencial da enfermagem ${ }^{(21)}$.

As ações educativas desenvolvidas por enfermeiros devem compreender a significação de sujeito e incentivar as pessoas a refletirem sobre seu compromisso sócio-ambiental, permitindo uma conduta ativa na transformação do processo de aprendizagem.

\section{CONSIDERAÇÕES FINAIS}

A presente reflexão teceu uma inter-relação entre a promoção da saúde, a educação ambiental e a Enfermagem. Nesse contexto, as mediações educativas devem favorecer a capacitação da comunidade à responsabilidade sócio-ambiental, com vistas ao bemestar ecológico.

O enfermeiro pode atuar nesse espaço, trazendo informações acerca da saúde ambiental e, consequentemente, humana. As atividades educativas sobre a saúde ambiental devem seguir os eixos da Promoção da Saúde descritos na Carta de Otawa, permitindo o desenvolvimento de habilidades pessoais para fortalecer o reforço da ação comunitária numa articulação coletiva e rever a formulação de políticas públicas para a criação de ambientes saudáveis e livres de poluição.

\section{REFERÊNCIAS}

1. Gein EAT. Ambientar arte na educação. In: Fhilippi Júnior A, Pelicion MCF, editores. Educação ambiental e sustentabilidade. Barueri: Manole; 2005. p. 102-13.

2. Van Eijck M, Roth WM. Improving science education for sustainable development. Plos Biol 2007; 5(12): e306.

3. Shiratori K, Costa TL, Formozo GA, Silva SA. Educação em saúde como estratégia para garantir a dignidade da pessoa humana. Rev Bras Enferm 2004; 57 (5): 617-9.

4. Moradilio EF, Oki MCM. Educação ambiental na universidade: construindo possibilidades. Quim Nova 2004; 27(2): 332-6.

5. Tavares C, Freire IM. "Lugar do lixo é no lixo": estudo de assimilação da informação. Cien Inf 2003; 32(2):125-35.

5. Buss PM. Uma introdução ao Conceito de Promoção da Saúde. In: Czeresnia D, Freitas CM, organizadores. Promoção da Saúde: conceitos, reflexões, tendências. Rio de Janeiro: Editora Fiocruz; 2003. p. 8-18.

6. Silva KL, Sena RR, Grillo MIC, Horta NC, Prado PMC. Educação em enfermagem e os desafios para a promoção de saúde. Rev Bras Enferm 2009; 62 (1): 86-91.

7. Ministério da Saúde (BR). Promoção da saúde: carta de Otawa. Declaração de Adelaide Sunsvall e Santa de Bogotá. Brasília: Ministério da Saúde; 2001 .

8. Nietsche EA, Backes VMS, Colomé CLM, Ceratti R do N, Ferroz F. Tecnologias educacionais, assistenciais e gerenciais: uma 
reflexão a partir da concepção dos docentes de Enfermagem. Rev Latino-am Enfermagem 2005; 12(3): 344-53.

9. Barroso MGT, Vieira NFC, Varela ZMV, organizadores. Educação em saúde: no contexto da promoção humana. Fortaleza: Edições Demócrito Rocha; 2003.

10. Torres CA. Da pedagogia do oprimido à luta contínua: a pedagogia política de Paulo Freire. In: Peter M, Peter L, Gadotti M, organizadores. Paulo Freire: poder, desejo e memórias da libertação. São Paulo: Artmed; 1998. p. 180-93.

11. Souza EM, Grundy E. Promoção da saúde, epidemiologia social e capital social: inter-relações e perspectivas para a saúde pública. Cad Saúde Pública 2004, 20 (2): 1354-60.

12. Marchiorato-Carneiro SM. Fundamentos epistemo-metodológicos da educação ambiental. Educar 2006; 27(1): 17 35 .

13. Carvalho ICM. As transformações na esfera pública e a ação ecológica: educação e política em tempos de crise da modernidade. Rev Bras Educ 2006; I I (32): I4I3-78.
14. Jacobi P. Educação ambiental, cidadania e sustentabilidade. Cad. de Pesquisa 2003; I 18(1): 189-205.

15. Grynszpan D. Educação em saúde e educação ambiental: uma experiência integradora. Cad Saúde Pública 1999; 15 (sup 2): 133-8.

16. Hillervik LJC, Hansson A-C, Weinehall RFL. Experiences of Swedish community health nurses working with health promotion and a patient-held health record. Scand I Caring Sci 2006; 20; 448-54.

17. Oliveira HM, Goncalves MJF. Educação em Saúde: uma experiência transformadora. Rev Bras Enferm 2004; 57(6): 761 3.

18. Olshansky E. Nurses and health promotion. J Prof Nurs 2007; 23(I): I-2I

19. Corrêa LB. O saber resíduos sólidos de serviços de saúde na formação acadêmica: uma contribuição da educação ambiental. Interface - Comunic Saúde Educ 2005; 9(18): 571-84.

20. Boff L. Saber cuidar: ética do humano - compaixão pela terra. Petrópolis: Vozes; 1999. 